\title{
The Influence of Student Ability and Family Background on Independent Admission Results of Universities in China
}

\author{
Yunfeng Luo ${ }^{1}$, Bingjie Liang ${ }^{1}$ and Hua Shen ${ }^{1, *}$ \\ ${ }^{1}$ School of Public Management, University of Electronic Science and Technology of China, Chengdu 611731, China \\ *Corresponding author. Email: shenhua7986@uestc.edu.cn
}

\begin{abstract}
As an important part of the higher education enrollment system in China, the independent admission policy has always attracted much attention. Whether the students with stronger ability are selected and whether fairness is taken into account during the independent admission are the focus of this paper. Using freshmen data from a top-40 university in western China, this study analyzed independent admission selection results by factor analysis and logistic regression method. It shows that student ability and family background have a great impact on the independent admission results. Students who have stronger abilities have been selected, and students with higher family economic status in the city are more likely to be accepted during independent admission. It can be seen that the selection efficiency of independent admission is high, but there is still space for promoting the fairness of independent admission.
\end{abstract}

Keywords: student ability, family background, independent admission, China

\section{INTRODUCTION}

How to ensure wider and fairer university admissions is one of the key and difficult points in the reform and development of university admission systems in various countries. It directly affects access to higher education. The issue of fair or equal access to universities has a long history. It is known in many countries that access to universities is not socially even[1][2]. In Britain, children of managers and professional workers are much more likely to enter university than those from poor or working class backgrounds[3]. Due to different political and economic backgrounds, education management systems, and social and cultural backgrounds, university admission systems in different countries present different characteristics. In the USA for example, Black and Latino students have been underrepresented among university students and, until the 1960s were often actively discriminated against. As a result, a number of universities have now introduced positive discrimination for black and minority students though this has been challenged.

In order to explore a new mechanism for selecting outstanding innovative talents, the Ministry of Education of China has implemented pilot programs for independent admission reform in some key universities across the country since 2003. The independent admission policy focuses on whether to select students who have more subject expertise and innovation ability than students admitted through the national college entrance examination (gaokao). However, due to the lack of good measurement mechanism, there are many fraudulent materials in independent admission, and the fairness of independent admission is questioned, and the quality of talent selection is difficult to guarantee. In 2019, the Ministry of Education of China further put forward stricter requirements for independent admission in three aspects: admission policy, admission procedures, and supervision and management to ensure fairness and justice in the process of independent admission and improve the quality of talent selection. Compared with the past, the independent admission policy in 2019 further reduces the preferential scores given to students, decreases the number of enrollment quotas and the enrollment subject, and increases the importance of physical fitness test (physical fitness test is to make middle school and students aware of the importance of physical exercise and to ensure that students enrolled in the university have good physical fitness). In addition, it is not allowed to simply use the papers, patents, and competitions organized by intermediaries as the basis for the primary selection. For the certificate of the event to be recognized, it is necessary to focus on the subject competition with high authority and strong credibility.

Independent admission is not only an important means for universities to improve the quality of enrollment, but also a way to distribute high-quality higher education resources. It is important to improve students' access to quality higher education. However, some universities have been found to have a problem of insufficient effectiveness and fairness in the process of independent admission. Therefore, both the government and public are particularly concerned about the status of independent admission, and understanding the status of independent admission is also important for further improving independent admission. 
The key questions of the paper are whether the students with stronger ability are selected and whether fairness is taken into account during the independent admission.

\section{LITERATURE REVIEW}

In the study of the factors affecting admission results, most empirical studies have shown that family background has a significant impact on admission results[4][5][6][7]. Although independent admission has selected students with outstanding academic performance and comprehensive quality, they are mainly from families with better economic conditions in the eastern cities[8]. Some scholars have found that in cases where the scores of written examinations are the same, the interview process in independent admission is more conducive to children from families with higher socioeconomic status [9]. Brian (2010) also found that the enrollment system has a tendency to favour students from intellectual elite families and urban students. [10] Some scholars have found that students whose father's occupation and education level is higher and whose family income is higher are more likely to be admitted through independent admission. Independent admission has worsened the injustice of the college entrance examination[11].

Scholars have mainly studied the influence of students family background on the independent admission results. Few studies discuss the influence of students' overall quality on the independent admission result. Few scholars have thoroughly explored the problems in the two selections of independent admission, and the proposed countermeasures to improve independent admission are not highly targeted.

Therefore, this study uses the data from a questionnaire survey of freshmen who had just started university education to analyze whether the students with stronger ability are selected and whether the independent admission give opportunities to students from less advantaged backgrounds by exploring the influence of student ability and family background on the two selection results of independent admission. Based on literature review, this paper proposes the following research hypotheses:

a. The overall ability of students has a significant impact on the results of independent admission. The stronger the students' overall ability, the higher the probability of passing two selections of independent admission.

b. Family background has a significant impact on the results of independent admission. The more advantaged the student's family background, the higher the probability of passing two selections of independent admission.

c. That residence has no significant effect on the results of independent admission. Students living in different regions or urban or rural areas have no significant difference in the likelihood of passing two selections.

\section{DATA AND METHODOLOGY}

\subsection{Data}

This study mainly used data from a 2018 freshmen questionnaire at a high-quality university, a first-class university located in Sichuan province. 4,920 questionnaires were distributed, 4,904 valid questionnaires were returned, and the questionnaire efficiency was as high as 93\%. Among them, 4,254 students didn't take the primary selection of independent admission and were admitted directly through gaokao score; 170 students only passed the primary selection of independent admission and then were admitted through gaokao score; 141 students passed the final selection of independent admission and were admitted by adding preferential score to their gaokao score.

\subsection{Methodology}

In order to try to measure the difference between those students in overall ability and family background, this paper mainly uses factor analysis and binary logistic regression models.

Factor analysis refers to a multivariate statistical analysis method that attributes some overlapping variables to a few unrelated composite factors. Through factor analysis, this study attributes the various variables in the questionnaire to several indicators to measure the students' overall ability, which lays a foundation for analyzing the influence of students' overall ability on the results of independent enrollment. The measurement of overall quality has always been a difficult part of the research in the field of education and psychology. There is no authoritative measurement scale for the measurement of students' overall ability. However, some scholars have found that the student engagement in high school has an important impact on student achievements at university. Comprehensive student engagement in school can not only improve the students' knowledge system, but also help students improve their quality in all aspects. Therefore, the status of student engagement in school can effectively reflect the overall quality of the students. In addition, in the review of independent admission policy, the subject expertise and innovative ability of students are the main content of the selection. Therefore, this study will examine the comprehensive quality from three aspects: student engagement, subject expertise and innovation ability.

National Survey of Student Engagement (NSSE) in America adheres to the "student-centered" assessment concept and surveys students' engagement in the form of questionnaires. The engagement indicators designed in the questionnaire survey are introduced by many countries and regions. Although the independent admission policy does not clearly define innovation ability, in the university's independent admission brochure, students who believe that 
they have innovation ability are students who can receive provincial or higher awards in the five disciplines of mathematics, biology, chemistry, physics, and informatics. On the basis of a comprehensive discussion of many scholars, Yue Ying (2017) proposed that innovation ability can be examined from three dimensions: innovative quality, innovative skills and innovative practice.[12]The requirements for subject expertise in the independent admission brochures of universities generally mean that students have a strong interest in the applied professions and have outstanding ability in the applied professions. Therefore, this study believes that subject expertise mainly includes two aspects: subject interest and subject ability. With reference to the engagement indicators of the 2016 NSSE project in the United States and Yue Ying's classification of innovation ability, this study selected 39 variables related to student engagement, innovation ability and subject expertise in the questionnaire, and we conducted KMO and Bartlett tests on 39 variables. As shown in Table 1 , the KMO statistic is 0.922 , and the Bartlett spherical test $\mathrm{P}$ value is less than 0.05 , indicating that this data is suitable for factor analysis.

Table 1. KMO and Bartlett's Test

\begin{tabular}{l|l|r|}
\hline \multicolumn{2}{|l|}{$\begin{array}{l}\text { Kaiser-Meyer-Olkin Measure of Sampling } \\
\text { Adequacy. }\end{array}$} & 0.922 \\
\hline $\begin{array}{l}\text { Bartlett's } \\
\text { Test of } \\
\text { Sphericity }\end{array}$ & Approx. Chi-Square & 101090.792 \\
\cline { 2 - 3 } & df & 741 \\
\cline { 2 - 3 } & Sig. & 0.000 \\
\hline
\end{tabular}

Selecting 39 variables for factor analysis, it is found that there are 8 initial eigenvalue variance contribution ratios greater than 1 , and the variance cumulative contribution rate reaches $63.8 \%$. Therefore, the 39 variables are divided into 8 indicators for measuring overall quality. These include:, subject interest and subject ability reflect the subject expertise of student; innovative quality, innovative skills and innovative practice; reflective \& integrative learning, learning strategies and quantitative reasoning.

To explore the impact of students' overall quality and family background on the opportunities for independent admission, we will regard "whether to pass the primary selection of independent admission" and "whether to pass the final selection of independent admission" as a dichotomous variable ("no" $=0$, "yes" $=1$ ). The binary logistic regression model is a typical model for studying the dependent variable as a dichotomous variable. Therefore, this paper mainly uses the binary logistic regression model to analyze the factors affecting individuals who pass the primary selection (final selection) of independent admission. Assuming that the probability of an individual passing the primary selection (final selection) is $\mathrm{P}$, the probability that the primary selection(final selection) cannot be passed is 1-P. Using Logit(P) as the dependent variable, a logistic regression model containing $\mathrm{i}$ independent variables is established as follows:

$$
\operatorname{Logit}(P)=\beta_{0}+\beta_{1} X_{1}+\beta_{2} X_{2}+\cdots+\beta_{i} X_{i}
$$

Among them, $x 1, x 2, x 3 \ldots .$. represents independent variable, beta 0 is a constant term, and beta1, beta2, beta3......are regression coefficients. The independent variable of gender, ethnicity and region are used to measure the personal characteristics of students. The independent variable of family income, parental education level and family residence are used to measure the family background of students.

\section{RESULT AND DISCUSSION}

Put the individual characteristics, overall quality, and family background into the binary logistic regression equation. The results are shown in Table2.

\subsection{Primary Selection}

It is found that male and Han students are more likely to pass the primary election of independent admission in the university we study. This may be because the university is a typical polytechnic university. The independent admission majors and exam content are biased towards science and engineering. Scholar have shown that boys are more inclined to choose science and engineering majors, and girls are more inclined to choose humanities and social sciences[13]. According to the 2010 census, the Han population accounts for $91.5 \%$ of the total population. Therefore, the reason why Han students are more likely to pass the primary selection is probably that the students who apply for independent admission are mainly Han students. Unlike previous research, we finds that the advantage of western students through the primary enrollment is more obvious than that of eastern students. This may be because the university studied is located in the western region and in the process of enrollment, it tends to recruit local students, which has made the western students have obvious advantages in the primary enrollment. Overall, the enrollment of the university in the local province meets the requirements of the Chinese Ministry of Education, that is, the university's local enrollment cannot exceed $30 \%$ of the total enrollment plan, However, in the independent enrollment, students from local province accounted for nearly $50 \%$ of the total number. It can be seen that there is a serious localization tendency in independent admission. Consistent with the findings of other scholars, we found that students whose father's occupation and education level is higher and whose family income is higher are more likely to pass primary selection. This may be because families with higher income can invest more in their children's education to enhance their children's overall quality, so their children are more likely to pass the primary election. Through the analysis of the questionnaire, we found that the higher the frequency of students with higher parental income, the higher the frequency of participation in academic clubs, etc. The proportion students in high income family who usually participate in activities such as student clubs is more than three times that of students in low income family. The educational level of parents has a positive impact on students' primary selection. This may be because parents who have received higher 
education are more likely to participate in the education process of their children. Studies have pointed out that as parents get higher education, the investment in children's learning facilities and the time spent with children will increase simultaneously[14]. In the process of preparing for independent admission, parents who get graduate education have a deeper understanding of the university's independent admission policies, can provide more guidance and help. Students living in capital cities have a higher probability of passing primary elections than students living in rural areas. In the independent admission brochures of 90 universities in 2018, it was generally stipulated that students who want to apply for independent admission need to win prizes in discipline competitions, science and technology competitions, and have papers or invention patents during high school. Due to the limitations of educational resources, rural students have far less understanding and participation in academic competition than urban students. In our questionnaire, we found $40 \%$ of rural and township students said that they did not know about various competitions, compared to only $34 \%$ of the students living in county level and above cities. The application conditions for independent admission will put rural students in a weak position.

Table 2. Regression analysis of influencing factors of independent admission selection results

\begin{tabular}{|c|c|c|c|}
\hline \multirow{2}{*}{ Influencing factors } & \multirow{2}{*}{ Specific variable } & Model $1^{\oplus}$ & \multirow{2}{*}{$\frac{\text { Model 2 }^{(2)}}{\operatorname{Exp}(B)}$} \\
\hline & & $\operatorname{Exp}(B)$ & \\
\hline $\begin{array}{c}\text { Gender } \\
\text { (Reference group: Female) }\end{array}$ & Male & $1.430^{*}$ & 0.833 \\
\hline $\begin{array}{c}\text { Nationality } \\
\text { (Reference group: Minority) }\end{array}$ & Han & $4.222 * * *$ & 0.620 \\
\hline \multirow{2}{*}{$\begin{array}{c}\text { Region } \\
\text { (Reference group: Central) }\end{array}$} & Western & $1.780 * * *$ & 1.194 \\
\hline & Eastern & 1.197 & $2.107 *$ \\
\hline \multirow{3}{*}{$\begin{array}{l}\text { Income } \\
\text { (Reference group: Low) }\end{array}$} & High & $8.503 * * *$ & 3.143 \\
\hline & Upper middle & $5.427 * *$ & 1.649 \\
\hline & Lower middle & 2.343 & 2.506 \\
\hline \multirow{5}{*}{$\begin{array}{c}\text { Father's education } \\
\text { (Reference group: Primary school or below) }\end{array}$} & Graduate or above & $4.981 * * *$ & 3.295 \\
\hline & Undergraduate & 1.974 & 1.622 \\
\hline & High vocational school & 1.698 & 1.474 \\
\hline & High school & 1.589 & 0.707 \\
\hline & Junior high school & 1.343 & 0.528 \\
\hline \multirow{5}{*}{$\begin{array}{c}\text { Mother's education } \\
\text { (Reference group: Primary school or below) }\end{array}$} & Graduate or above & $2.916 * *$ & 0.415 \\
\hline & Undergraduate & 1.898 & 0.259 \\
\hline & Junior college & 1.180 & $0.161 * *$ \\
\hline & High school & 1.684 & 0.351 \\
\hline & Junior high school & 1.573 & 0.838 \\
\hline \multirow{4}{*}{$\begin{array}{c}\text { Residence } \\
\text { (Reference group: Rural) }\end{array}$} & Provincial city & $2.131 * *$ & $3.317 *$ \\
\hline & Prefecture-level city & $1.982 * *$ & 2.009 \\
\hline & County & $1.848^{*}$ & 1.592 \\
\hline & Township & 1.754 & 0.691 \\
\hline \multirow{2}{*}{ Subject expertise } & Subject interest & $1.165 * *$ & 0.878 \\
\hline & Subject ability & $1.704 * * *$ & 1.201 \\
\hline \multirow{3}{*}{ Innovation ability } & Innovative quality & $0.765 * * *$ & $0.761 *$ \\
\hline & Innovative skills & 1.106 & $1.359 * *$ \\
\hline & Innovative practice & 1.042 & 1.131 \\
\hline \multirow{3}{*}{ Student engagement } & Reflective \&Integrative Learning & 1.013 & 0.841 \\
\hline & Learning Strategies & $0.797 * * *$ & 1.126 \\
\hline & Quantitative Reasoning & $1.167 * *$ & 0.944 \\
\hline
\end{tabular}

Note: (DThe dichotomous variable of model 1 is "whether to pass the primary selection of independent admission."

(2) The dichotomous variable of model 2 is "whether to pass the final selection of independent admission"

The students' subject interest and subject ability have a significant positive impact on the primary selection. This shows that the independent admission in the primary selection process does focus on subject expertise.

\subsection{Final Selection}

Consistent with other scholars' research, eastern students are more likely to pass final selection. It may be because the school is no longer inclined to recruit local students in the final election and the provinces in the eastern region have more advantages in terms of education financial investment and teacher strength. The eastern students can 
get more educational resources and receive more overall quality training. Therefore, eastern students have better performance than central and western students in the final selection process.

However, we found the probability of students whose mother got junior college education passing the final selection is significantly less than students whose mother only got primary school education. In the questionnaire, we found that $38 \%$ of mothers who were only in primary education were unemployed, while only $10 \%$ of mothers who received junior college education were unemployed. Mothers who only receive primary school education may be more aware of the benefits of higher education, and a significant proportion of mothers who receive primary school education are unemployed, which gives them more time to supervise their children's learning and improve their ability to test.

Students living in provincial cities are more likely to pass the final selection than those living in rural areas. There are two main reasons for this apparent urban-rural difference. On the one hand, it may be because the examination questions in final selection are mostly based on urban life experience, such as high-speed rail operation, shared bicycles, mobile payment, etc., and there are few problems based on rural life experience. This makes the students living in the city more advantaged in the final selection. On the other hand, although the government has been increasing investment in rural education, there is still a very significant difference in the quality of basic education in urban and rural areas. Compared with urban students, rural students are relatively difficult to obtain high-quality educational resources, and their performance in overall quality is relatively poor, which undoubtedly increases the difficulty for rural students to pass final selection.

Innovative skills have a significant positive impact on students' self-enrollment primary selection, indicating that final selection has a good effect on selecting students with better innovation skills. However, the innovation quality has a significant negative impact on the final selection result, indicating that students who have performed better in innovation quality have not been selected.

\section{CONCLUSION}

The above analysis verifies our two hypotheses. The students' overall ability and family background do have a significant impact on the results of independent admission. Students' overall ability and family background have a greater impact on the primary selection results. The stronger the overall ability, the more advantaged the family background is, the easier it is for students to pass the primary selection. Although the students' overall ability and family background have less influence on the final selection results, they also have a positive impact on the results of final selection. However, regarding our third hypothesis, family residence still has a significant impact on the two selections, students from western cities are more likely to pass primary election, and students from eastern cities are more likely to pass final elections.
In order to improve the fairness and efficiency of independent admission, we propose corresponding suggestions for the two stages of primary and final selection.

In primary selection, the university should first conduct a rigorous review of the application materials submitted by the students and carefully check the authenticity, credibility and participation of the relevant materials. Besides, in the material review, it is necessary to pay attention to the students' overall ability evaluation results in the middle school, and give the rural students who lack the competition award certificate a chance to fully express themselves[15].

In final selection, the university should establish a set of scientific and effective assessment standards, independent admission as a means of talent selection. In addition, the test questions should take into account the urban-rural differences in student life experience, scientifically demonstrate the written test or interview content.

\section{ACKNOWLEDGMENT}

This research was funded by National Social Science Foundation of China, grant number BFA200072.

\section{REFERENCES}

[1] John Jerrim and Anna Vignoles."University access for disadvantaged children: a comparison across countries." Higher Education 70.6(2015): doi:10.1007/s10734-015-9878-6.

[2] Michael Donnelly and Ceryn Evans. "A 'homeinternational' comparative analysis of widening participation in UK higher education." Higher Education 77.1(2019): doi:10.1007/s10734-018-0260-3.

[3] Review, by, Roger, L., \& Geiger. "Origins and Destinations: Family, Class and Education in Modern Britain by A. H. Halsey; A. H. Heath; J. M. Ridge." European Journal of Education 15.3 (1980):313-316.

[4] Selcuk R. Sirin. "Socioeconomic Status and Academic Achievement: A Meta-Analytic Review of Research." Review of Educational Research 75.3(2005): doi:10.3102/00346543075003417.

[5] Josh Kinsler and Ronni Pavan. "Family Income and Higher Education Choices: The Importance of Accounting for College Quality." 5.4(2011): doi:10.1086/663649.

[6] Jo Blanden and Stephen Machin. "Educational Inequality and The Expansion of UK Higher 
Education." Scottish Journal of Political Economy 60.5(2013): doi:10.1111/sjpe.12024.

[7] Kosutic, I. . "The Role of Cultural Capital in Higher Education Access and Institutional Choice." Ceps Journal Center for Educational Policy Studies Journal 7.1(2017):149-169.

[8] Xun ZF and Wang QH. "Independent recruitment :a battle field for elite students. " Tsinghua Journal of Education 32.02(2011):56-63. doi:10.14138/j.10014519.2011.02.012. (In Chinese)

[9] Limin Liu, et al."Independent Freshman Admission and Educational Inequality in the Access to Elite Higher Education." Chinese Sociological Review 46.4(2014): doi:10.2753/CSA2162-0555460403.

[10] Brian P. An."The relations between race, family characteristics, and where students apply to college." Social Science Research 39.2(2009): doi:10.1016/j.ssresearch.2009.08.003.

[11] Anna Zimdars. "Elite Higher Education Admissions in the Arts and Sciences: Is Cultural Capital the
Key?." Sociology 43.4(2009): doi:10.1177/0038038509105413.

[12] Yue Y. "The status of independently-enrolled students' creativity and its influence mechanism. " Fudan Education Forum 15.03(2017):18-24.

doi:10.13397/j.cnki.fef.2017.03.004. (In Chinese)

[13] Lu GS, Liu S and Zhong YP. "Analysis of gender differences and influencing factors in higher education demand and professional choice. "Higher Education Research 30.10(2009):14-29. doi:CNKI:SUN:HIGH.0.2009-10-004. (In Chinese)

[14] Qi X. "Parental education level and children's human capital investment - Investigation and research on rural households in China. "Education Research Monthly.09(2013):73-79. doi:10.16477/j.cnki.issn16742311.2013.09.021. (In Chinese)

[15] Vikki Boliver, et al."Will the Use of Contextual Indicators Make UK Higher Education Admissions Fairer?." Education Sciences 5.4(2015): doi:10.3390/educsci5040306. 